\title{
Radical resection and local coverage of hidradenitis suppurativa - acne inversa: analysis of results
}

\section{Tratamento cirúrgico de hidradenite supurativa - acne inversa: ressecção radical e cobertura local: análise de resultados}

Rogério Rafael da Silva Mendes'; Rafael Ferreira Zatz'; Miguel luiz Antonio Modolin', eCbC-SP; Fábio de Freitas Busnardo'; Rolf GEMPERLI', TCBC-SP

\begin{abstract}
A B S T R A C T
Objective: to evaluate the primary outcome of local complications and late recurrence in patients with hidradenitis suppurativa undergoing radical resection and specific reconstruction. Methods: we conducted a retrospective analysis of the medical records of patients attended by the Plastic Surgery Service of the Clinics Hospital, Medical School, USP, between 2010 and 2016. We included patients who underwent radical resection of hidradenitis suppurativa in advanced stage and reconstruction through primary closure, grafts or flaps. Results: we analyzed 34 lesions in 19 patients, of which $64.5 \%$ had local complications, though with $73.5 \%$ efficient healing after 12 weeks postoperatively. We observed late recurrence in $47 \%$, but in isolation, $22.2 \%$ of the reconstructions with locoregional flaps had recurrence after one year. Conclusion: extensive and radical resection of the disease associated with locoregional flap coverage (pedicled or perforating) has been shown to be the best management in terms of late results.
\end{abstract}

Keywords: Hidradenitis Suppurativa. Surgical Flaps. Folliculitis. Cutaneous Fistula. Skin Abnormalities. Reconstruction.

\section{INTRODUCTION}

$\mathrm{H}$ idradenitis suppurativa (HS), or acne inversa, consists of a cutaneous pathology of affection of the apocrine glands and the pilosebaceous complex, characteristic of the intertriginous regions, more frequent in the axillary and inguinal areas. It evolves with occlusion of the pores of the hair follicle and formation of abscesses with subdermal paths that fistulize to the skin. There is recurrent infection followed by chronic inflammatory process and consequent cicatricial retraction. Clinically it begins with erythema and papules, advancing to the formation of abscesses, fistulas and fibrotic bands, and causes pain and suppuration of characteristic fetid odor, with local architectural disfiguration. The literature shows several classifications for gradation of HS, among them the Hurley classification, which defines conservative or surgical treatment according to the degree of evolution of the lesions, but does not confer treatment efficacy ${ }^{1-4}$.

It is a disease of great repercussion in the quality of life and socioeconomic commitment of the affected individuals. It affects mainly patients between puberty and the fifth decade of life, with a high prevalence ( $1 \%$ to $4 \%$ of the population) and a significant incidence
$(6 / 100,000 \text { inhabitants) })^{5-8}$.

There is no consensus regarding the standard treatment of HS, but it is widely accepted that extensive resection and local coverage is crucial in advanced lesions. In this work, we present the retrospective analysis of the experience of the Plastic Surgery Service of the Clinics Hospital of the Faculty of Medicine of the University of São Paulo in the treatment of advanced hidradenitis suppurativa lesions with radical resection and local coverage. The primary objective of this study is to evaluate the incidence of complications and late recurrence regarding the studied variables, with emphasis on the reconstruction employed.

\section{METHODS}

We designed the study as a retrospective analysis based on the review of medical charts, evaluating the patients seen between 2010 and 2016 with the diagnosis of advanced stage (Hurley III) hidradenitis suppurativa, submitted to surgery according to defined inclusion criteria: radical resection under general anesthesia and immediate or late reconstruction. We included cases with a minimum follow-up of one year. We excluded patients

1 - Hospital das Clínicas, School of Medicine, University of São Paulo (USP), Discipline of Plastic Surgery, São Paulo, SP, Brazil. 
with doubtful diagnosis for hidradenitis suppurativa and those submitted to split resections, under local anesthesia, or not submitted to specific reconstruction.

We performed descriptive analysis of demographic data, including age, weight, BMI, preoperative parameters (hemoglobin and serum albumin, smoking), topographic distribution of lesions, and specific reconstruction. Regarding the outcome studied, we carried out a descriptive analysis of the treatment efficacy through the following categories: minor local complications, major local complications (those requiring reoperation), systemic complications, adequate healing after 12 weeks of surgery, late recurrence after one year of follow-up.

We applied inferential statistical analysis for the two primary outcomes studied: local complications and late recurrence, according to the reconstruction modality employed. For the analysis of the association between local complications and late recurrence regarding the reconstruction employed, we used the likelihood ratio test, assigning a significant $p$ value $<0.05$. We used an MS-Excel spreadsheet, in its version of MS-Office 2013, to tabulate the data, and the IBM SPSS (Statistical Package for Social Sciences), version 23.0, to perform the statistical analysis.

\section{RESULTS} In the period, 19 patients were followed, are compiled in table 1. resulting in 29 primary surgeries, for a total of 34 lesions approached, all based on the total resection of the affected area. The mean age was 32 years (15-27), mean weight of $75 \mathrm{~kg}(55-112)$, with a mean BMl of $28 \mathrm{~kg} / \mathrm{m}^{2}$ (22-38.5). Regarding the preoperative parameters, mean baseline hemoglobin was 12.28g/dl (9.7-14.7), and mean serum albumin of $4.2 \mathrm{~g} / \mathrm{dl}$ (3.2-4.7). Among the patients in the study, $42 \%$ were smokers.

As for the distribution of the lesions, six (31\%) patients presented lesions in a single topography and $13(69 \%)$ patients had multiple lesions. There was predominance of axillary lesions (19-56\%), followed by gluteal lesions (8-23\%) and inguinal ones (7-21\%).

Of the 34 primary lesions approached, 30 (88\%) were treated with immediate reconstruction through primary closure, grafts and cutaneous flaps. In four (22\%) cases, diagnosed with active infection and inadequate bed for immediate coverage, we opted for late reconstruction after debridement and negative pressure therapy. The dimensions of the lesions were not a criterion of choice for immediate or late reconstruction.

Regarding the reconstruction employed, in 17 (50\%) cases, locoregional cutaneous flap was used based on known vascular territory through pedicle or presumed perforator, in eight $(23.5 \%)$, primary closure, in seven $(20.5 \%)$, at random, and in two (6\%), grafts. These data

Table 1. Data categorized according to the injuries approached and performed procedures.

\begin{tabular}{|c|c|c|c|c|c|}
\hline \multirow[t]{2}{*}{ Injury Approached } & \multirow[t]{2}{*}{ Number of Cases } & \multicolumn{2}{|c|}{ Time of Reconstruction } & \multicolumn{2}{|c|}{ Reconstruction Employed } \\
\hline & & & & Primary Closure & $2(10.5 \%)$ \\
\hline \multirow{4}{*}{ Axillary } & \multirow{4}{*}{$19(56 \%)$} & Immediate & $16(84.3 \%)$ & Partial Skin Graft & $2(10.5 \%)$ \\
\hline & & Late * & $3(15.7 \%)$ & Local Flap & $5(26.5 \%)$ \\
\hline & & & & Locoregional Flap & $10(52.5)$ \\
\hline & & & & Primary Closure & $1(12.5 \%)$ \\
\hline \multirow{4}{*}{ Gluteal } & \multirow{4}{*}{$8(23 \%)$} & Immediate & 7 (87.5\%) & Partial Skin Graft & $0(0 \%)$ \\
\hline & & Late * & $1(12.5 \%)$ & Local Flap & $1(12.5 \%)$ \\
\hline & & & & Locoregional Flap & $6(75 \%)$ \\
\hline & & & & Primary Closure & $4(57 \%)$ \\
\hline \multirow{3}{*}{ Inguinal } & \multirow{3}{*}{$7(21 \%)$} & Immediate & $7(100 \%)$ & Partial Skin Graft & $0(0 \%)$ \\
\hline & & Late * & $0(0 \%)$ & Local Flap & $1(14 \%)$ \\
\hline & & & & Locoregional Flap & $2(28 \%)$ \\
\hline & \multirow{4}{*}{$34(100 \%)$} & & & Primary Closure & $7(20.5 \%)$ \\
\hline \multirow{3}{*}{ Total } & & Immediate & $30(88.3 \%)$ & Partial Skin Graft & $2(6 \%)$ \\
\hline & & Late * & $4(11.7 \%)$ & Local Flap & $7(20.5 \%)$ \\
\hline & & & & Locoregional Flap & $18(53 \%)$ \\
\hline
\end{tabular}

* Use of vacuum therapy between debridement and definitive reconstruction. 
Figures 1 and 2 demonstrate post-resection lesions with fasciocutaneous flaps and muscle sparing reconstructions of gluteal and axillary hidradenitis perforators.
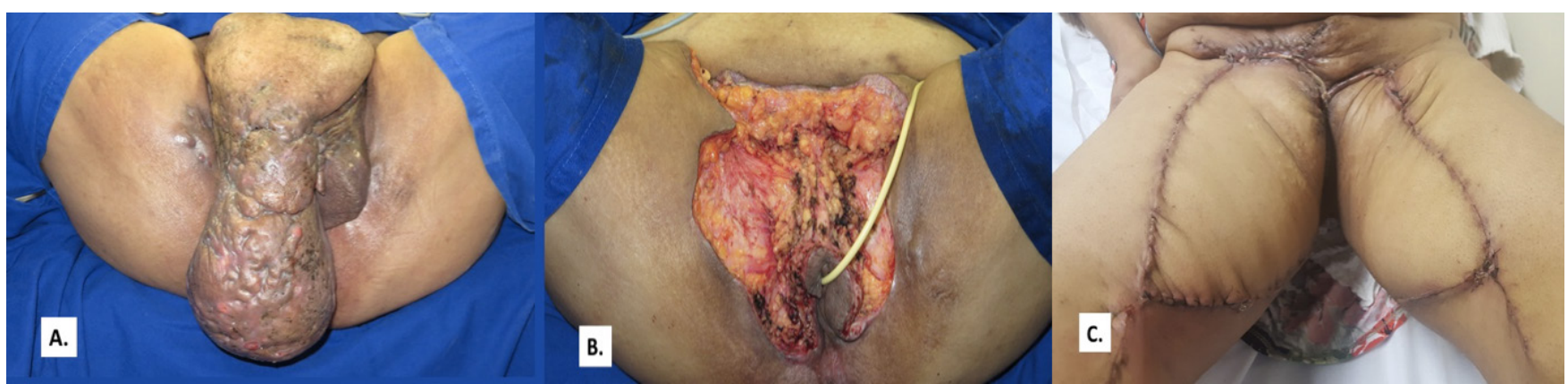

Figure 1. A) Example of Hurley III perineal hidradenitis suppurativa, refractory to clinical treatment. B) Area to be reconstructed after resection of the lesion. C) Late postoperative outcome of reconstruction with bilateral, VY-advancement fasciocutaneous flaps of the medial thigh based on femoral artery perforators.

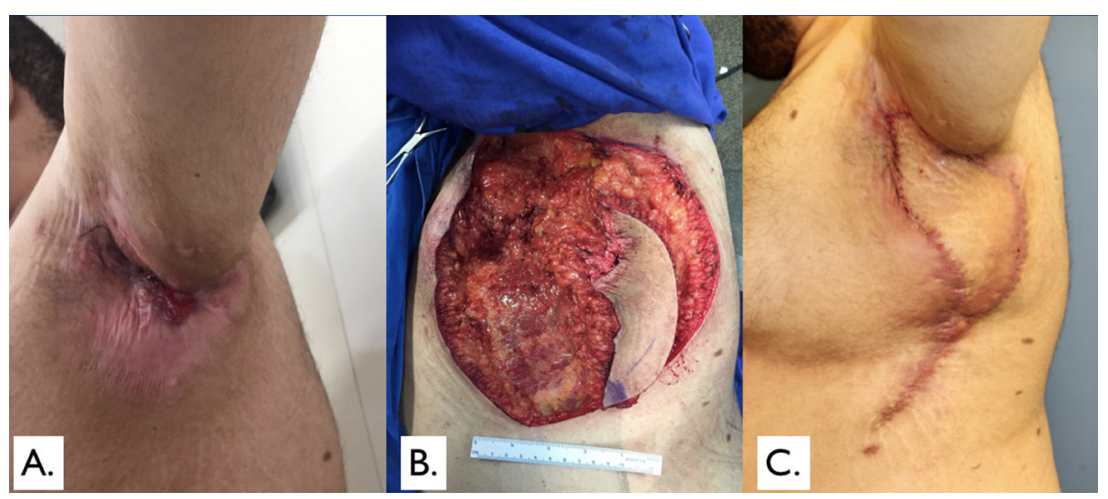

Figure 2. A) Example of Hurley III axillary hidradenitis suppurativa, refractory to clinical treatment. B) Dissected fasciocutaneous transposition flap based on thoracic-dorsal and lateral thoracic arteries perforators at rest in its bed, adjacent to the area to be reconstructed. C) Surgical outcome on the 17 th postoperative day.

Twenty-two (64.5\%) lesions presented local healing after 12 weeks of surgery. At late follow-up, 17 complications: dehiscence, surgical wound infection, (50\%) lesions did not present late recurrence after one hematoma and seroma. Of these, seven were major year of treatment, while $16(47 \%)$ lesions presented late complications, requiring reoperation within a period of up recurrence after one year of follow-up. There was loss of to 30 days due to infection, dehiscence or loss of prior reconstruction. There was no systemic complication. follow-up of one patient with an axillary lesion submitted to reconstruction with local cutaneous flap. Table 2 shows

Twenty-five (73.5\%) lesions showed adequate the data according to the affected region.

Table 2. Data categorized according to complications, wound healing and late recurrence.

\begin{tabular}{lccccc}
\hline $\begin{array}{c}\text { Injury } \\
\text { Approached }\end{array}$ & $\begin{array}{c}\text { Number of } \\
\text { Cases }\end{array}$ & $\begin{array}{c}\text { Local } \\
\text { Complications ** }\end{array}$ & Reoperation & $\begin{array}{c}\text { Efficient healing after } \\
12 \text { weeks }\end{array}$ & $\begin{array}{c}\text { Late recurrence } \\
\text { after } 1 \text { year }\end{array}$ \\
\hline Axillary & $19(56 \%)$ & $11(58 \%)$ & $4(21 \%)$ & $15(78 \%)$ & $6(33 \%) *$ \\
Gluteal & $8(23 \%)$ & $6(75 \%)$ & $2(25 \%)$ & $7(87.5 \%)$ & $3(37.5 \%)$ \\
Inguinal hernia & $7(21 \%)$ & $5(71 \%)$ & $1(14 \%)$ & $3(57 \%)$ & $7(100 \%)$ \\
Total & 34 & $22(64.5 \%)$ & $7(20.5 \%)$ & $25(73.5 \%)$ & $16(47 \%)$ \\
\hline
\end{tabular}

* Local Complications involved dehiscence, infection, hematoma, seroma, graft loss. There are cases with concomitant complications; ** Computation for a total of 18 cases (one case with loss of follow-up). 
The reconstruction strategy that presented the highest rate of complications was primary closure ( $85.7 \%$ of the cases), represented by dehiscence and surgical wound infection. This strategy also showed the highest recurrence rates $(100 \%)$. On the other hand, reconstruction with locoregional flaps had lower late recurrence, in $22 \%$ of the cases.
As for local complications, we found no statistically significant difference in the different reconstructions employed, with a p-value of 0.611 . However, when analyzing late recurrence, the different reconstructions employed displayed a statistically significant difference, with a p-value of 0.004 . Tables 3 and 4 show these data, respectively.

Table 3. Data categorized according to the incidence of local complications and the reconstruction used.

\begin{tabular}{lccc}
\hline \multicolumn{1}{c}{ Reconstruction Used } & yes & no & Total \\
& $1(50 \%)$ & $1(50 \%)$ & \\
\hline Graft & $6(85.71 \%)$ & $1(14.29 \%)$ & 2 \\
Primary closure & $4(57.14 \%)$ & $3(42.86 \%)$ & 7 \\
Local Random Flap & $11(61.11 \%)$ & $7(38.89 \%)$ & 18 \\
Pedicled/perforating Flap & $22(64.71 \%)$ & $12(35.29 \%)$ & 34 \\
Total & & & 7 \\
\hline
\end{tabular}

Table 4. Data categorized according to the incidence of late recurrence and the reconstruction used.

\begin{tabular}{lccc}
\hline \multicolumn{1}{c}{ Reconstruction Used } & Les & no recurrence & Total \\
\hline Grafting & $1(50 \%)$ & $1(50 \%)$ & 2 \\
Primary Closure & $7(100 \%)$ & $0(0 \%)$ & 7 \\
Local Random Flap & $4(66.67 \%)$ & $2(33.33 \%)$ & 6 \\
Pedicled/perforating Flap & $4(22.22 \%)$ & $14(77.78 \%)$ & 18 \\
Total & $16(48.48 \%)$ & $17(51.52 \%)$ & 33 \\
\hline
\end{tabular}

These results demonstrate that the type of reconstruction employed did not interfere with the incidence of local complications, but it was determinant in the differences found in late recurrence rates. The use of locoregional (pedicled or perforating) flaps was related to the most effective results, particularly in reconstructions of axillary and gluteal lesions with respective treatment success of $90 \%$ and $66.6 \%$, without disease relapse after a one-year follow-up. These data are compiled in table 5. 
Table 5. Late recurrence in absolute figures according to the lesion approached and reconstruction used.

\begin{tabular}{lccc}
\hline \multicolumn{1}{c}{ Lesion + Reconstruction } & \multicolumn{2}{c}{ Late recurrence } \\
& yes & no & unavailable \\
\hline Axillary + skin graft & 1 & 1 & - \\
Axillary + Primary Closure & 3 & 0 & - \\
Axillary + Local Random Flap & 2 & 2 & 1 \\
Axillary + Pedicled/perforating Flap * & 1 & 9 & - \\
Inguinal + skin graft & 0 & 0 & - \\
Inguinal + Primary Closure & 4 & 0 & - \\
Inguinal + Local Random Flap & 1 & 0 & - \\
Inguinal + Pedicled/perforating Flap ** & 1 & 0 & - \\
Gluteal + skin graft & 0 & 0 & - \\
Gluteal + Primary Closure & 1 & 0 & - \\
Gluteal + Local Random Flap & 1 & 0 & - \\
Gluteal + Pedicled/perforating Flap *** & 2 & - \\
* Recurrence in one latissimus dorsi myocutaneous flap and none in seven TAP flaps and one latissimus dorsi myocutaneous flap; ** Recurrence in \\
one gluteal- thigh flap; *** Recurrence in one gluteal VY-advancement fasciocutaneous flap and in one medial thigh flap, and no recurrence in one \\
gluteal fold flap, two posterior thigh VY-advancement fasciocutaneous flaps and one medial thigh VY-advancement fasciocutaneous flap.
\end{tabular}

\section{DISCUSSION}

Hidradenitis suppurativa consists of an inflammatory disease of recurrent character. Characterized by involvement of the apocrine glands and the pilosebaceous complex, it has important social stigma. The first description of the disease was made by Leper in 1839, while Verneuil associated it, in 1854, with the apocrine glands. The clinical picture was presented in detail by Lane and Brunstig, and the surgical procedure, by Conway and others in the last century ${ }^{4}$.

Changing life habits and hygiene care are fundamental in managing the disease and preventing its evolution. However, advanced cases often require more aggressive and sometimes invasive therapy for disease control, when considered incurable ${ }^{8,9}$. In addition to local hygiene measures, clinical management with topical and systemic antibiotics has been described, and more recently, the use of immunobiologicals in the adjuvant treatment of the disease, such as inhibitors of TNF-beta, with encouraging, though preliminary, results ${ }^{8,10}$. The surgical approach with partial or complete excision of the affected area, followed by immediate or late reconstruction, with or without the use of vacuum pressure therapy, is a wellestablished approach in the field of action of plastic surgeons $s^{5-7}$.

Several studies have evaluated the best treatment alternatives, but the methods of evaluation are variable and often unclear, in addition to the lack of randomized controlled trials, which makes a definitive conclusion on the subject difficult. Even so, surgery is as an important and definitive part of treatment. A review study comparing drainage vs. split resection versus wide resection revealed a relapse rate of $100 \%, 42.8 \%$ and $27 \%$, respectively, after 72 months of follow-up ${ }^{4}$. Nevertheless, even with local resection referred to as "broad radical" - standard recommended treatment -, the literature reveals variable rates of relapse in late follow-up, of $19 \%$ to $74 \%{ }^{11-14}$. Although our study did not attempt to evaluate recurrence according to the resection employed, with inclusion of only advanced cases submitted to extensive/radical resection, the absolute incidence of late recurrence for the so-called broad/radical resection of $47 \%$, independent of the studied area or reconstruction type, was concordant with the current literature. The lowest late recurrence rates with radical resection of the lesions is well established 
when compared with the split resection ${ }^{14-19}$.

In this study, we included patients with advanced lesions, Hurley grade III (diffuse involvement with multiple abscesses and fistulous tracts interconnected along the affected area, associated or not with scar retraction and purulent discharge of characteristic odor), submitted to surgery with radical resection and local coverage. Graduation scales are useful for classifying severity and guiding the management of injuries, but do not assess treatment efficacy. In this context, "Hidradenitis Suppurativa Clinical Response (HiSCR)" defines treatment success as a reduction of at least $50 \%$ in total inflammatory abscesses and nodules, without any increase in the formation of new abscesses or draining fistulas after 12 weeks of treatment with immunobiologicals. This was used as a parameter, in this retrospective study, to adopt the 12-week period as an end-point for analysis of effective healing after extensive resection followed by reconstruction and, additionally, the 12-month period was established as a cutoff for evaluation of lesions late recurrence $\mathrm{e}^{2,4}$.

Our focus was to study the relationship between reconstruction strategy in relation to complications and late recurrence. Although it does not directly influence disease treatment, the reconstruction strategy seems to be a limiting potential of the previous resection by the surgeon. Thus, resections with larger reconstructions, performed by a trained surgeon, are usually truly broad and radical. This was evident by the lower late recurrence rates displayed by the radical resection strategy followed by coverage with locoregional flaps ${ }^{18-20}$.

We believe that the comorbidities and life habits (obesity, smoking, diabetes and immunosuppression) present in this sample were factors associated with the high complication rate $(64.5 \%)$ in this study. Factors related to the surgical technique, such as tension sutures, inadvertent compression or traction of the pedicle, poorly placed grafts or poorly prepared beds can also be determinants of major complications that require reoperation. The main surgical indications were infection and dehiscence of the operative wound. In these cases, we employed culture-guided antibiotic therapy and antibiogram, debridement, use of negative pressure therapy (in case of total dehiscence) and reconstruction with resuturing, grafting or flap rotation. Factors related to the wounds, such as bacterial contamination and distribution area of the apocrine glands and hair follicles are additional factors associated with the greater complication and recurrence rates.

The older literature suggests that both fasciocutaneous and musculocutaneous flaps demonstrate a marked increase in blood flow to the recipient beds, although the rate of collagen deposition and bacterial clearance is greater in the musculocutaneous flaps ${ }^{21,22}$. With the technical improvements in fasciocutaneous flap collection and perforating flaps, the most recent evidence on osteomyelitis of the lower limbs and sternum and on the recurrence of pressure ulcers do not demonstrate inferiority of the fasciocutaneous flaps compared with myocutaneos ones ${ }^{23-26}$. With this reasoning applied to the experience of our Service with fasciocutaneous and perforating flaps extrapolated to the scenario of hidradenitis suppurativa, we also prefer reconstruction with fasciocutaneous and perforating flaps based on known territories whenever possible 20,27-29. Especially in the more prevalent axillary lesions, reconstructions with perforating flaps based on the territory of the lateral thoracic and thoracic-dorsal arteries have shown morphofunctional success in terms of recurrence and function of the affected limb ${ }^{20}$.

Being $a$ in university hospital service, in our series the inguinal lesions presented $100 \%$ of late recurrence, which we attributed to the greater concentration of pilosebaceous complexes and proximity of the femoral vessels, which could limit the resection by the young, training surgeon. At the other extreme, the treatment of axillary lesions showed the best results, in that the flap based on perforators of the lateral thoracic and thoraco-dorsal arteries did not show late recurrence, while the latissimus dorsi myocutaneous flap displayed late recurrence in one (33\%) of the cases.

Late reconstruction seems to be the best option for infected surgeries, where the negative pressure dressing shows better results. Due to logistics, lack of hospital beds and availability of surgical rooms, immediate reconstruction was used whenever possible, but in the four infected cases in which reconstruction was late, we employed bridge negative pressure therapy. Of 
these, only one presented a late recurrence ${ }^{13}$.

In this study, $73.5 \%$ of the patients presented efficient healing 12 weeks after surgery. On the other hand, late recurrences were evident in $47 \%$ of the cases, demonstrating the recurrent and progressive character of the disease. Reconstruction with flaps render more efficient healing and less recurrence compared with primary closure. Inferential analysis was statistically significant for the different recurrence rates according to the reconstructions employed. Thus, the strategy of radical resection associated with locoregional flap coverage (pedicle or perforator) has been shown to be the best management in terms of late results.

Although this is an original study, in an attempt to draw a specific relation between the outcome of the surgical treatment of hidradenitis suppurativa with the reconstruction employed, the limitations of the study should be weighed. Although it is a retrospective study, with a variable population in terms of age, gender, lesion topography and several reconstructions employed in addition to limited casuistry, it served the purpose of analyzing the trend of viable treatment for different presentations of the disease studied in a tertiary public service to attend high complexity pathologies. Radical resection may be considered an essential part of the management of hidradenitis suppurativa in advanced degree, and reconstruction should not be a limitation to treatment.

The results obtained in the study corroborate this finding, evidencing a lower rate of relapse with more extensive resections, reconstructed with locoregional flaps, but there is a need for prospective, randomized studies that deepen the knowledge on the subject, based on this peculiar evaluation.

\title{
R E S U M O
}

\begin{abstract}
Objetivo: avaliar o desfecho primário de complicações locais e de recidiva tardia em pacientes com diagnóstico de hidradenite supurativa submetidos a ressecção radical e reconstrução específica. Métodos: análise retrospectiva baseada nos prontuários dos pacientes atendidos pelo serviço universitário de Cirurgia Plástica do Hospital das Clínicas da Faculdade de Medicina da USP, entre 2010 a 2016. Foram incluídos apenas pacientes submetidos a ressecções radicais de hidradenite supurativa em grau avançado, submetidos à reconstrução através de fechamento primário, enxertos ou retalhos. Resultados: foram analisadas 34 lesões, das quais $64,5 \%$ apresentaram complicações locais, porém com 73,5\% de cicatrização eficiente após 12 semanas de pós-operatório. Recidiva tardia foi observada em $47 \%$, porém, isoladamente, $22,2 \%$ das lesões reconstruídas com retalhos locorregionais apresentaram recidiva tardia após um ano. Conclusão: a estratégia de ressecção ampla e radical da doença associada à cobertura da ferida com retalho locorregional (pediculado ou perfurante) demonstrou ser o melhor manejo em termos de resultados tardios.
\end{abstract}

Descritores: Hidradenite Supurativa. Retalhos Cirúrgicos. Foliculite. Fístula Cutânea. Anormalidades da Pele. Reconstrução.

\section{REFERENCES}

1. García-Martínez FJ, Pascual JC, López-Martín I, PereyraRodríguez JJ, Martorell Calatayud A, Salgado-Boquete $L$, et al. [Update of hidradenitis suppurativa in Primary Care]. Semergen. 2017;43(1):34-42. Spanish.

2. Ingram JR, Woo PN, Chua SL, Ormerod AD, Desai N, Kai $A C$, et al. Interventions for hidradenitis suppurativa: a Cochrane systematic review incorporating GRADE assessment of evidence quality. $\mathrm{Br} J$ Dermatol. 2016;174(5):970-8.
3. DeFazio MV, Economides JM, King KS, Han KD, Shanmugam VK, Attinger CE, et al. Outcomes after combined radical resection and targeted biologic therapy for the management of recalcitrant hidradenitis suppurativa. Ann Plast Surg. 2016;77(2):217-22.

4. Kimball AB, Sobell JM, Zouboulis CC, Gu Y, Williams DA, Sundaram M, et al. HiSCR (Hidradenitis Suppurativa Clinical Response): a novel clinical endpoint to evaluate therapeutic outcomes in patients with hidradenitis suppurativa from the placebo-controlled portion of a phase 2 adalimumab study. J Eur Acad Dermatol 
Venereol. 2016;30(6):989-94.

5. McMillan K. Hidradenitis suppurativa: number of diagnosed patients, demographic characteristics, and treatment patterns in the United States. Am J Epidemiol. 2014;179(12):1477-83.

6. Vazquez BG, Alikhan A, Weaver AL, Wetter DA, Davis MD. Incidence of hidradenitis suppurativa and associated factors: a population-based study of Olmsted County, Minnesota. J Invest Dermatol. 2013;133(1):97-103.

7. Esmann S, Jemec GB. Psychosocial impact of hidradenitis suppurativa: a qualitative study. Acta Derm Venereol. 2011;91(3):328-32.

8. von der Werth JM, Williams HC. The natural history of hidradenitis suppurativa. J Eur Acad Dermatol Venereol. 2000;14(5):389-92.

9. Falola RA, DeFazio MV, Anghel EL, Mitnick CD, Attinger CE, Evans KK. What heals hidradenitis suppurativa: surgery, immunosuppression, or both? Plast Reconstr Surg. 2016;138(3 Suppl):219S-29S.

10. Lee EY, Alhusayen R, Lansang P, Shear N, Yeung J. What is hidradenitis suppurativa? Can Fam Physician. 2017;63(2):114-20.

11. Mehdizadeh A, Hazen PG, Bechara FG, Zwingerman $\mathrm{N}$, Moazenzadeh M, Bashash $M$, et al. Recurrence of hidradenitis suppurativa after surgical management: a systematic review and meta-analysis. J Am Acad Dermatol. 2015;73(5 Suppl 1):S70-7.

12. Canoui-Poitrine F, Le Thuaut A, Revuz JE, Viallette C, Gabison G, Poli F, et al. Identification of three hidradenitis suppurativa phenotypes: latent class analysis of a cross-sectional study. J Invest Dermatol. 2013;133(6):1506-11.

13. Alharbi Z, Kauczok J, Pallua N. A review of wide surgical excision of hidradenitis suppurativa. BMC Dermatol. 2012;12:9.

14. Mandal A, Watson J. Experience with different treatment modules in hidradenitis suppuritiva: a study of 106 cases. Surgeon. 2005;3(1):23-6.

15. Rompel R, Petres J. Long-term results of wide surgical excision in 106 patients with hidradenitis suppurativa. Dermatol Surg. 2000;26(7):638-43.

16. Chen YE, Gerstle T, Verma K, Treiser MD, Kimball AB, Orgill DP. Management of hidradenitis suppurativa wounds with an internal vacuum-assisted closure device. Plast Reconstr Surg. 2014;133(3):370e-377e.

17. Bieniek A, Matusiak L, Okulewicz-Gojlik D, Szepietowski JC. Surgical treatment of hidradenitis suppurativa: experiences and recommendations. Dermatol Surg. 2010;36(12):1998-2004.

18. Ritz JP, Runkel N, Haier J, Buhr HJ. Extent of surgery and recurrence rate of hidradenitis suppurativa. Int J Colorectal Dis. 1998;13(4):164-8.

19. Harrison BJ, Mudge M, Hughes LE. Recurrence after surgical treatment of hidradenitis suppurativa. $\mathrm{Br}$ Med J (Clin Res Ed). 1987;294(6570):487-9.

20. Busnardo FF, Coltro PS, Olivan MV, Busnardo AP, Ferreira MC. The thoracodorsal artery perforator flap in the treatment of axillary hidradenitis suppurativa: effect on preservation of arm abduction. Plast Reconstr Surg. 2011;128(4):949-53.

21. Gosain A, Chang N, Mathes S, Hunt TK, Vasconez L. A study of the relationship between blood flow and bacterial inoculation in musculocutaneous and fasciocutaneous flaps. Plast Reconstr Surg. 1990;86(6):1152-62.

22. Calderon W, Chang N, Mathes SJ. Comparison of the effect of bacterial inoculation in musculocutaneous and fasciocutaneous flaps. Plast Reconstr Surg. 1986;77(5):785-94

23. Hong JPJ, Goh TLH, Choi DH, Kim JJ, Suh HS. The efficacy of perforator flaps in the treatment of chronic osteomyelitis. Plast Reconstr Surg. 2017;140(1):179-88.

24. Henry SL. Discussion: The efficacy of perforator flaps in the treatment of chronic osteomyelitis. Plast Reconstr Surg. 2017;140(1):189-91.

25. Yamamoto $Y$, Ohura $T$, Shintomi $Y$, Sugihara $T$, Nohira K, Igawa $\mathrm{H}$. Superiority of the fasciocutaneous flap in reconstruction of sacral pressure sores. Ann Plast Surg. 1993;30(2):116-21.

26. Sameem M, Au M, Wood T, Farrokhyar F, Mahoney J. A systematic review of complication and recurrence rates of musculocutaneous, fasciocutaneous, and perforator-based flaps for treatment of pressure sores. Plast Reconstr Surg. 2012;130(1):67e-77e.

27. Barreiro GC, Millan LS, Nakamoto H, Montag E, Tuma Junior P, Ferreira MC. Reconstruções pelveperineais com uso de retalhos cutâneos baseados em vasos perfurantes: experiência clínica com 22 casos. Rev Bras Cir Plast. 2011;26(4):680-4. 
28. Milcheski DA, Mendes RRDS, Freitas FR, Zaninetti G, Moneiro AA Júnior, Gemperli R. Brief hospitalization protocol for pressure ulcer surgical treatment: outpatient care and one-stage reconstruction. Rev Col Bras Cir. 2017;44(6):574-81.

29. Coltro PS, Busnardo FF, Mônaco Filho FC, Olivan MV, Millan LS, Grillo VA, et al. Outcomes of immediate internal pudendal artery perforator flap reconstruction for irradiated abdominoperineal resection defects. Dis Colon Rectum. 2017;60(9):94553.
Received in: 08/01/2018

Accepted for publication: 22/03/2018 Conflict of interest: none.

Source of funding: none.

Mailing address:

Rafael Ferreira Zatz

E-mail: rafaelzatz@yahoo.com.br / zatzrafael@gmail.com

\section{(cc) BY}

